\title{
SIMPLE QUANTIFIED AND VALIDATED STABILITY INDICATING STRESS DEGRADATION STUDIES OF ORAL ANTI-DIABETIC AGENT DAPAGLIFLOZIN BY RP-HPLC METHOD
}

\section{ARULSELVAN MURUGESAN ${ }^{*}$, MUKTHINUTHALAPATI MATHRUSRI ANNAPURNA ${ }^{2}$}

1Department of Pharmaceutical Analysis, AIKTC School of Pharmacy, New Panvel 410206 Dist-Raigad (M. S.) India, ${ }^{2}$ Department of Pharmaceutical Analysis and Quality Assurance, GITAM Institute of Pharmacy, GITAM (Deemed to be University), Visakhapatnam 530045, India

*Email: arulrama@gmail.com

Received: 29 Oct 2021, Revised and Accepted: 08 Dec 2021

\section{ABSTRACT}

Objective: This method is focused on developing a precisely simplified and more accurate Reverse Phase-High Pressure Liquid Chromatography (RP-HPLC) method for the determination of Dapagliflozin in bulk and pharmaceutical dosage form as per guidelines of International Council for Harmonization (ICH)

Methods: Evaluation and validation carried out using the RP-HPLC ZORBAX (C18) column ( $250 \mathrm{x} 4.6 \mathrm{~mm}, 5 \mu \mathrm{m}$ particle size) with a mobile phase consisting of Phosphate Buffer: Acetonitrile: Methanol in a ratio of 55:40:05 (v/v/v) at a flow rate of $1 \mathrm{ml} / \mathrm{min}$ with an injection volume of $10 \mu \mathrm{l}$.

Results: Dapagliflozin was eluted at $2.12 \pm 0.05 \mathrm{~min}$ and detected at $225 \mathrm{~nm}$. The regression equation y $=55762 \mathrm{x}-29679$ found to be linear with correlation coefficient $\mathrm{r}^{2}$ value of 0.9997 . The developed RP-HPLC method was conveniently validated as per the ICH guidelines and found method was robust, sensitive, accurate, selective, specific, precise and linear.

Conclusion: The proposed method was found to be accurate, precise, and robust for API and pharmaceutical dosage form as per experimentation analysis. The above developed method was found to be satisfied for Active Pharmaceutical Ingredient (API) and pharmaceutical formulation of Dapagliflozin to study its degradation products.

Keywords: Dapagliflozin, Forced stability, ICH, SGLT2, Stress degradation, RP-HPLC, Validation

(C) 2022 The Authors. Published by Innovare Academic Sciences Pvt Ltd. This is an open access article under the CC BY license (https://creativecommons.org/licenses/by/4.0/) DOI: https://dx.doi.org/10.22159/ijap.2022v14i1.43482. Journal homepage: https://innovareacademics.in/journals/index.php/ijap

\section{INTRODUCTION}

Dapagliflozin $\left(\mathrm{C}_{21} \mathrm{H}_{25} \mathrm{ClO}_{6}\right)$ is chemically namedas (1S)-1, 5-anhydro1-C-[4-chloro-3-[(4-ethoxyphenyl) methyl] phenyl]-D-glucitol, physical appearance of it is a white to off white solid with melting range of $74-78{ }^{\circ} \mathrm{C}$. The molecular weight is $408.873 \mathrm{~g} / \mathrm{mol}$. It has a good solubility profile in organic solvents such as methanol, and dimethyl sulfoxide but is poorly soluble in aqueous media.

Fig. 1: Chemical structure of dapagliflozin

Dapagliflozin is an oral anti-diabetic agent which belongs to Selective Sodium-glucose co-transporter-2 (SGLT2) Inhibitor. Sodium-glucose co-transporter-2 (SGLT2) inhibitors are expressed in proximal renal tubules and are responsible for $90 \%$ reabsorption of glucose filtered by kidneys. Sodium-glucose co-transporter 2 (SGLT2) lowers reabsorption of filtered glucose into the body by decreasing the renal threshold for glucose (RTG) which leads to the production of a supplement to urinary glucose excretion in diabetic patients [1, 2]. Dapagliflozin is a C-glycosyl comprising beta-Dglucose in which the anomeric hydroxyl group is replaced by a 4chloro-3-(4-ethoxybenzyl) phenyl group to improve glycemic control in adults with type 2 diabetes along with improved lifestyle. Adults with proper diet and exercise showed improved glycemic control by Gliflozin derivatives by inhibiting glucose resorption in the proximal tubule of the nephron and causing glycosuria $[2,3]$.

Various studies performed and reported for estimation of gliflozin derivatives and Dapagliflozin using Ultraviolet-Visible (UV-Vis) spectroscopy as single dosage form [4-6] as well as in its combination form [7-10].

Few researchers studied its pharmacokinetics in biological fluids by selecting Bioanalytical methods [11-13] and there are some other methods reported like HPTLC, Fluorescence and capillary electrophoresis for estimation of Dapagliflozin, in combination with other anti-diabetic agents like Saxagliptin/Metformin [14-16].

Literature review shows minimal methods has been developed and reported for Dapagliflozin estimation by HPLC as an individual drug $[3,17-20]$ and in combination with Saxagliptin and Metformin [2124] where the reported methods has vary retention time, high run time and more consumption of organic solvents for the estimation. This study focused on developing an RP-HPLC method of Dapagliflozin which is more economical, new, rapid, precise and accurate with a good amount of separation, consuming less organic solvents for separation as compared to the reported research work mentioned above.

\section{MATERIALS AND METHODS}

Chemicals and reagent

For this study, HPLC grade Acetonitrile (ACN), HPLC grade Methanol $(\mathrm{MeOH}), \mathrm{HPLC}$ grade O-Phosphoric acid (OPA) from Merck (Mumbai, India) and HPLC grade water of SD fine-Chem Ltd; Mumbai were utilized. Market samples of FORXIGA $10 \mathrm{mg}$ tablets of Dapagliflozin were purchased from a local chemist shop.

Instrumentation and optimized chromatographic conditions

Shimadzu 2010CHT HPLC system supplied with a gradient pump connected to a UV detector set at $225 \mathrm{~nm}$ used. Lab solution software (5.5.2 Version) was used for data acquisition and for system suitability 
calculations. A $0.001 \mathrm{gm}$ sensitive electronic analytical weighing balance Shimadzu and an Ultra-sonicator (Equibtron) were used in this entire study. Thermal stability studies were carried out in an ITherm dry air oven. Optimized chromatographic conditions for the developed method summarized in (table 1).

Table 1: Optimized conditions for the validated developed method

\begin{tabular}{ll}
\hline Parameter & Chromatographic conditions \\
\hline Column & ZORBAX C $18_{18}(250 \times 4.6 \mathrm{~mm}, 5 \mu \mathrm{m})$ \\
Mobile phase & Phosphate buffer: Acetonitrile: \\
& Methanol in a ratio of $55: 40: 05(\mathrm{v} / \mathrm{v} / \mathrm{v})$ \\
Solvent & Dilute the solute in Mobile phase \\
Flow rate & $1.0 \mathrm{ml} / \mathrm{min}$ \\
Column oven temperature & $28^{\circ} \mathrm{C}$ \\
Detection Wavelength & $225 \mathrm{~nm}$ \\
Injection volume & $10 \mu \mathrm{l}$ \\
Retention time & $2.12 \pm 0.5 \mathrm{~min}$. \\
\hline
\end{tabular}

\section{Preparation of $0.025 \mathrm{M}$ phosphate buffer}

$3.4 \mathrm{~g}$ of potassium dihydrogen orthophosphate weighed and transferred into a $1000 \mathrm{ml}$ volumetric flask and made the volume with Distilled water. Phosphate buffer $\mathrm{pH}$ was adjusted to 4 with OPA and filtered the solution using $0.45 \mu \mathrm{m}$ membrane filters, sonicated it before use.

\section{Preparation of mobile phase}

$550 \mathrm{ml}$ of phosphate buffer solution, $400 \mathrm{ml}$ of Acetonitrile and 50 $\mathrm{ml}$ of methanol were mixed in the correct proportion to prepare the mobile phase. The prepared mobile phase was degassed using the ultrasonicator and filtered using $0.45 \mu \mathrm{m}$ vacuum filters. The mobile phase prepared for this experiment was also used as diluent for the entire sample and standard preparation.

\section{Preparation of stock solution}

$10 \mathrm{mg}$ Dapagliflozin weighed and transferred into a $10 \mathrm{ml}$ volumetric flask, dissolved and diluted up to the mark with Mobile phase prepared. The solution was ultrasonicated for $10 \mathrm{~min}$ to get 1 $\mathrm{mg} / \mathrm{ml}$ solution of Dapagliflozin $(1000 \mu \mathrm{g} / \mathrm{ml})$, further dilutions were made as per the requirement by mixing it in diluent and filtered through $0.45 \mu \mathrm{m}$ and degassed before injection.

\section{Preparation of sample solution}

Twenty Dapagliflozin tablets were accurately weighed and triturated to get a fine powder. A $10 \mathrm{mg}$ equivalent weight tablet powder was transferred into a $100 \mathrm{ml}$ volumetric flask and dissolved in methanol. The solution was ultra-sonicated for $10 \mathrm{~min}$ and made the volume with methanol. The tablet sample solution was then filtered through whatman filter paper (No. 41) and utilized for preparing sample solution for the assay.

\section{Method validation}

The developed method was validated for different prescribed parameters like accuracy, specificity, robustness, precision and linearity as per guidelines of ICH Q2A and Q2B [25, 26].

\section{Linearity}

To perform the calibration method, a series of solutions over the range of $10,20,30,40,50,60,80,100,120$ and $180 \mu \mathrm{g} / \mathrm{ml}$ of Dapagliflozin were prepared and $10 \mu \mathrm{l}$ of each solution was injected into the HPLC system to record peak area of the chromatogram. Calibration curve plotted against the concentration of the solutions on the $\mathrm{x}$-axis and its corresponding peak area on the $y$-axis.

\section{Precision}

Intra-day and Inter-day Precision variation was analyzed by selecting concentrations $5 \mu \mathrm{g} / \mathrm{ml}$ (lower concentration) $10 \mu \mathrm{g} / \mathrm{ml}$ (middle concentration) and $15 \mu \mathrm{g} / \mathrm{ml}$ (higher concentration) Dapagliflozin and injecting that sample into HPLC system at different schedule time to measure the RT and peak area. The respective peak areas for different concentrations of Intra-day and Inter-day Precision were calculated and reported.

\section{Accuracy}

Recovery studies carried out by preparing different concentration solution of Dapagliflozin (80\%, $100 \%$ and $120 \%$ by adding 18 $\mu \mathrm{g} / \mathrm{ml}, 20 \mu \mathrm{g} / \mathrm{ml}$ and $22 \mu \mathrm{g} / \mathrm{ml}$ into $10 \mu \mathrm{g} / \mathrm{ml}(100 \%)$ solution of three replicate drug samples $(n=3)$.

\section{Robustness}

Deliberate variation method conducted by changing the method parameters such as flow rate $( \pm 0.2 \mathrm{ml} / \mathrm{min})$, temperature $\left( \pm 2{ }^{\circ} \mathrm{C}\right)$, mobile phase $( \pm 3 \mathrm{ml})$ and wavelength $( \pm 2 \mathrm{~nm})$ determines the robustness of the selected method. A $10 \mu \mathrm{g} / \mathrm{ml}$ solution of Dapagliflozin utilized for conducting robustness study.

\section{Forced degradation studies}

The stability indicating property of the developed HPLC method carried out by Force degradation studies as per ICH recommended guidelines. Dapagliflozin was subjected to acidic, alkaline, oxidative, photolytic and thermal conditions to study its degradation property. All solutions utilized for this study were diluted from the Sample stock solution prepared and kept with concentration of $1000 \mu \mathrm{g} / \mathrm{ml}$.

Acidic degradation performed by taking $1 \mathrm{ml}$ of stock solution and treating it with $9 \mathrm{ml}$ of $0.1(\mathrm{~N}) \mathrm{HCl}$ for $1 \mathrm{~h}$ in a thermostat maintained at $80^{\circ} \mathrm{C}$ in laboratory condition. Alkali degradation was performed by taking a known $1 \mathrm{ml}$ of stock solution and treating it with $9 \mathrm{ml}$ of $0.1(\mathrm{~N}) \mathrm{NaOH}$ for $1 \mathrm{~h}$ in a thermostat condition maintained at $80^{\circ} \mathrm{C}$. For oxidative degradation, the $10 \mathrm{ml}$ of the stock solution was pipette out and transferred into a $250 \mathrm{ml}$ round bottom flask. The contents were then mixed with oxidative agent $30 \% \mathrm{H}_{2} \mathrm{O}_{2}(90 \mathrm{ml})$. A volume of $10 \mu \mathrm{l}$ was injected into the HPLC system to measure peak height, peak area and retention time at multiple points and diluted to $10 \mathrm{ml}$ using diluents.

A crushed fine powder of Dapagliflozin (100 mg) was exposed to UV light $(254 \mathrm{~nm})$ for $2 \mathrm{~d}$ on a neat and clean surface. After the exposure period, a known amount of drug was transferred into a $10 \mathrm{ml}$ volumetric flask, diluted with diluent and the triplicate solution was injected into the HPLC system.

A crushed fine powder of Dapagliflozin $(100 \mathrm{mg}$ ) was exposed to thermal energy in a hot air oven at a temperature of $80^{\circ} \mathrm{C}$ for $48 \mathrm{~h}$. After the exposure period, a known amount of drug was transferred into $10 \mathrm{ml}$ volumetric flask, diluted with diluent and the triplicate solution has been injected into the HPLC system to measure peak height, area and retention time.

\section{Table 2: Optimized conditions for stress degradation studies}

\begin{tabular}{ll}
\hline Stress applied & Stress conditions \\
\hline Acidic & $9 \mathrm{ml}$ of $0.1(\mathrm{~N}) \mathrm{HCl}$ for $1 \mathrm{~h}$ at $80^{\circ} \mathrm{C}$ \\
& $9 \mathrm{ml}$ of $01(\mathrm{~N}) \mathrm{HCl}$ for $1 \mathrm{~h}$ at $80^{\circ} \mathrm{C}$ \\
Alkaline & $9 \mathrm{ml}$ of $0.1(\mathrm{~N}) \mathrm{NaOH}$ for $1 \mathrm{~h} \mathrm{at} 80^{\circ} \mathrm{C}$ \\
& $9 \mathrm{ml}$ of $01(\mathrm{~N}) \mathrm{NaOH}$ for $1 \mathrm{~h}$ at $80^{\circ} \mathrm{C}$ \\
Oxidative & $10 \%$ oxidative reagent $\mathrm{H}_{2} \mathrm{O}_{2}(90 \mathrm{ml})$ \\
& $30 \%$ oxidative reagent $\mathrm{H}_{2} \mathrm{O}_{2}(90 \mathrm{ml})$ \\
Thermolytic & $100 \mathrm{mg}$ powdered sample kept at $80^{\circ} \mathrm{C}$ for $48 \mathrm{~h}$ \\
& $100 \mathrm{mg}$ powdered sample kept at $80^{\circ} \mathrm{C}$ for $48 \mathrm{~h}$ \\
Photolytic (UV & $100 \mathrm{mg}$ powdered sample kept under UV light \\
light) & for $24 \mathrm{~h}$ \\
& $100 \mathrm{mg}$ powdered sample kept UV light for $48 \mathrm{~h}$ \\
\hline
\end{tabular}

\section{RESULTS}

The developed method quantified and validated as per the ICH guidelines prescribed for evaluating pharmaceutical dosage formulations $[25,26]$.

\section{System suitability}

The chromatogram of the blank, Standard Dapagliflozin and sample Dapagliflozin provided in (fig. 2) with a summary of its optimized conditions reported in (table 3 ). 
Table 3: System suitability parameter report in optimized conditions

\begin{tabular}{lllll}
\hline S. No. & Injection no & RT & Area & USP plate \\
\hline 1 & Injection 1 & 2.12 & 552631 & 4948 \\
2 & Injection 2 & 2.13 & 552024 & 4997 \\
3 & Injection 3 & 2.12 & 551926 & 4947 \\
4 & Injection 4 & 2.12 & 551749 & 4956 \\
5 & Injection 5 & 2.13 & 552772 & 4986 \\
6 & Injection 6 & 2.12 & 552038 & 4998 \\
Mean & & & 552190 & \\
SD & & 411.84 & \\
\%RSD & & 0.07 & \\
\hline
\end{tabular}

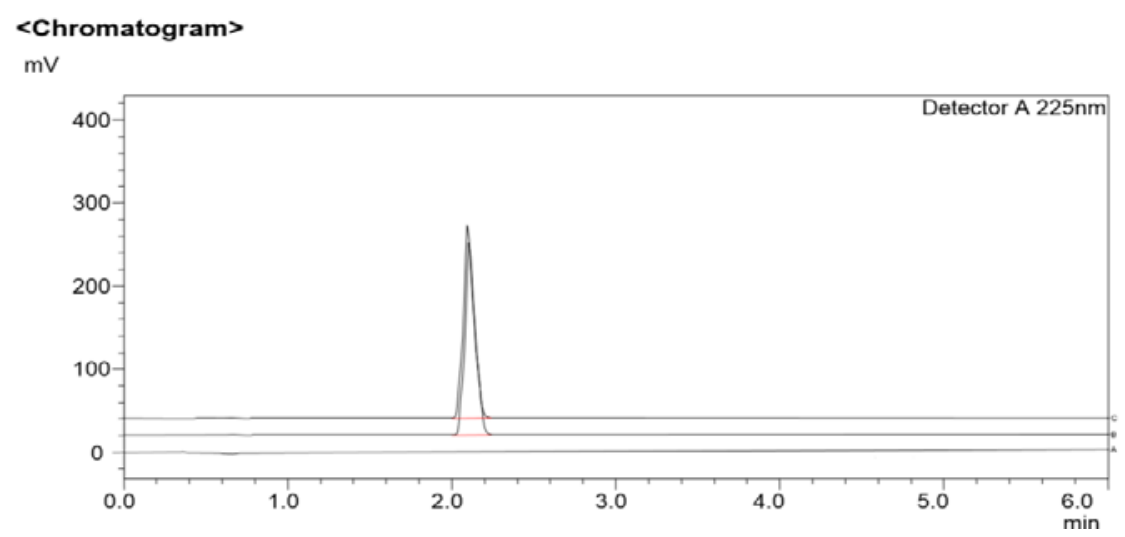

Fig. 2: Typical chromatogram of dapagliflozin in optimized condition A-Blank, B-standard and C-DAPA sample

\section{Linearity}

The correlation coefficient of regression value and intercept value were calculated using the formula $y=55762 x-29679\left(r^{2}=0.9997\right)$

(fig. 3) respectively, and obtained values are summarized in (table 4).

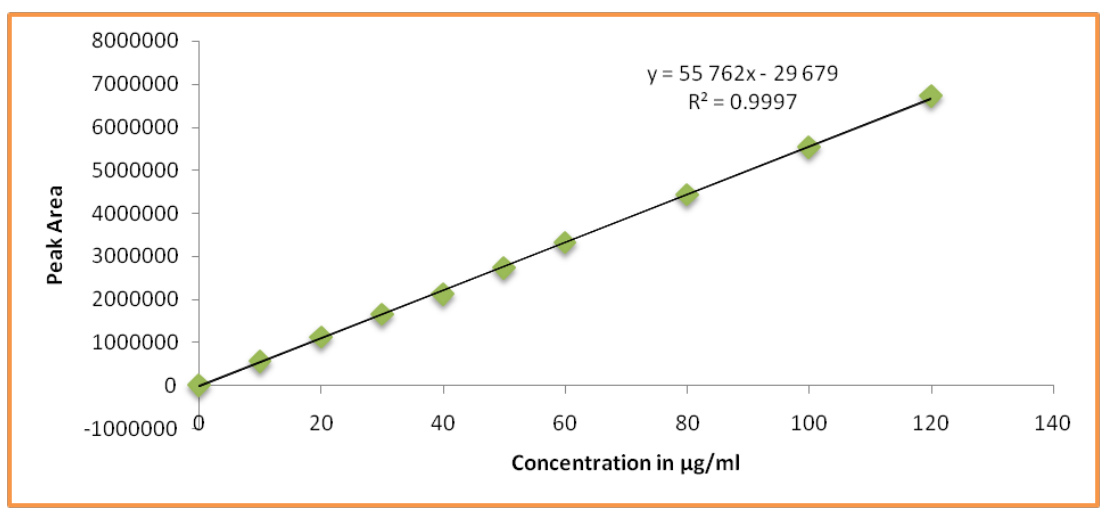

Fig. 3: Calibration curve of dapagliflozin at $225 \mathrm{~nm}$ wavelength

Table 4: Linearity results

\begin{tabular}{lll}
\hline S. No. & Concentration $(\boldsymbol{\mu g} / \mathbf{m l})$ & ${ }^{*}$ Mean peak area \pm SD $(\% \mathbf{R S D})$ \\
\hline 1 & 0 & 0 \\
2 & 10 & $552084 \pm 1024.80(0.19)$ \\
3 & 20 & $1122300 \pm 2525.75(0.23)$ \\
4 & 30 & $1646080 \pm 3366.04(0.20)$ \\
5 & 40 & $2112737 \pm 4986.14(0.24)$ \\
6 & 50 & $2722510 \pm 5967.67(0.22)$ \\
7 & 60 & $3315573 \pm 6682.89(0.20)$ \\
8 & 80 & $4425123 \pm 5053.81(0.11)$ \\
9 & 100 & $5530461 \pm 6060.31(0.11)$ \\
10 & 120 & $6708924 \pm 10104.11(0.15)$ \\
Slope & & 55762 \\
Intercept & & -29679.29 \\
Coefficient correlation value $\mathrm{r}^{2}$ & 0.9998 \\
\hline
\end{tabular}

mean $\pm \operatorname{SD}(n=3)$ 


\section{Accuracy}

The \% Mean recovery for Dapagliflozin was found to be 98.90 , 99.10 and 98.51 for $80 \%, 100 \%$ and $120 \%$, respectively and these results are promising and within acceptable limits of 98-102.
The \% RSD for Dapagliflozin was found to be $0.14,0.30$ and 0.23 , which is within limit of 2 and its high value of recoveries at different concentrations indicates the proposed method is accurate. The accuracy data of the proposed method is summarized in (table 5A)

Table 5A: Accuracy studies of dapagliflozin

\begin{tabular}{lllll}
\hline Spiked concentration $(\boldsymbol{\mu g} / \mathbf{m l})$ & Total concentration $(\boldsymbol{\mu g} / \mathbf{m l})$ & ${ }^{*}$ mean peak area \pm SD $(\% \mathbf{R S D})$ & Drug found $(\boldsymbol{\mu g} / \mathbf{m l})$ & Recovery $(\%)$ \\
\hline $8(80 \%)$ & 18 & $982495 \pm 1353.52(0.14)$ & 17.80 & 98.90 \\
$10(100 \%)$ & 20 & $1093955 \pm 3300.26(0.30)$ & 19.82 & 99.10 \\
$12(120 \%)$ & 22 & $1196119 \pm 2747.26(0.23)$ & 21.67 & 98.51 \\
\hline
\end{tabular}

mean $\pm \mathrm{SD}(\mathrm{n}=3)$

Table 5B: Precision studies of dapagliflozin

\begin{tabular}{llll}
\hline Concentration $(\boldsymbol{\mu g} / \mathbf{m l})$ & Intra-day & Inter-day \\
\cline { 2 - 4 } & "mean peak area $\mathbf{*}$ SD & \% RSD & ${ }^{*}$ mean peak area \pm SD \\
\hline 5 & $269594 \pm 600.93$ & 0.22 & $269803 \pm 607.02$ \\
10 & $549317 \pm 549.62$ & 0.10 & $548323 \pm 1769.78$ \\
15 & $823856 \pm 2026.11$ & 0.25 & $825106 \pm 2186.40$ \\
\hline
\end{tabular}

mean $\pm S D(n=3)$

\section{Precision}

Precision method performed by injecting three replicates of standard solutions $(5,10$ and $15 \mu \mathrm{g} / \mathrm{ml}$ concentration) within a day at different time intervals. The Intra-day and Inter-day precision studies were carried out and the result is summarized in terms of $\%$ RSD. The \% RSD values of Intra-day and Inter-day for Dapagliflozin are less than $2 \%$ (Intra-day $0.34,0.10,0.25$ and Inter-day $0.25,0.32$, 0.26 ) which reveal that the proposed method is precise (table $5 \mathrm{~B}$ ).

\section{Robustness}

The deliberate variation for this method was performed by robustness parameters like varying the flow rate, detector wavelength, Column temperature, and change in mobile phase composition. No palpable change in mean retention time $\left(\mathrm{R}_{\mathrm{t}}\right)$, mean $\%$ assay and $\%$ RSD and also assay results are within the acceptable limit of $\leq 2$. The tailing factor and plate count are within acceptable limits i.e., $>2500$ and $<2.0$, respectively. The \% RSD obtained was 1.26-1.79 for Dapagliflozin which is less than $2.0 \%$ indicating the proposed method is Robust. Summary of robustness reports under different conditions (change in flow rate, temperature and wavelength) are summarized in (table 6).

\section{Analysis of marketed formulation}

The Content of Dapagliflozin in the FORXIGA $10 \mathrm{mg}$ tablets was determined by the proposed analytical method. The assay value calculated by assaying 6 samples of the Dapagliflozin, the percentage value found to be 99.05 with standard deviation 0.3 and \% relative standard deviation of 0.273 . The mean concentration of Dapagliflozin in the given sample FORXIGA was found to be $9.91 \mathrm{mg}(99.05 \% \mathrm{w} / \mathrm{v})$. The obtained assay values were within the acceptable limit (98-102\%) against the amount claimed in the label (table 7).

Table 6: Result of robustness method

\begin{tabular}{llll}
\hline S. No. & Parameters & Condition & *Mean peak area \pm SD (\% RSD) \\
\hline 1 & Flow rate & $(0.8 \mathrm{ml} / \mathrm{min})$ & $541023 \pm 8843(1.63)$ \\
2 & Flow rate & $(1.0 \mathrm{ml} / \mathrm{min})$ & \\
3 & Flow rate & $(1.2 \mathrm{ml} / \mathrm{min})$ & $530816 \pm 9506(1.79)$ \\
4 & Wavelength & $223 \mathrm{~nm}$ & \\
5 & Wavelength & $225 \mathrm{~nm}$ & $539553 \pm 6824(1.26)$ \\
6 & Wavelength & $227 \mathrm{~nm}$ & \\
7 & Temperature & $26^{\circ} \mathrm{C}$ & $534576 \pm 8888(1.65)$ \\
8 & Temperature & $28^{\circ} \mathrm{C}$ & \\
9 & Temperature & $30{ }^{\circ} \mathrm{C}$ & \\
10 & Mobile phase & $(43: 57)$ & \\
11 & Mobile phase & $(45: 55)$ & $(47: 53)$ \\
12 & Mobile phase & & \\
\hline
\end{tabular}

mean $\pm \operatorname{SD}(n=3)$

Table 7: Assay estimation of dapagliflozin tablets

\begin{tabular}{llll}
\hline Formulation & Labeled claim $\mathbf{( m g )}$ & Amount found*(mg) & Recovery* (\%) \\
\hline Brand 1 & 10 & 9.91 & 99.05 \\
\hline
\end{tabular}

\section{Stress degradation studies}

Physiochemical variations of Dapagliflozin were studied by implementing stress degradation studies as per ICH guidelines from the stressed stability studies, it was clear that the drug withstands chemical parameters such as acid hydrolysis alkaline hydrolysis and oxidation.

At the same time a high amount of degradation was observed in the sample kept on irradiation with UV light (fig. 4). Obtained 
chromatogram for the assay of stress sample is shown in (fig. 4). The concentration of the obtained degradation products analogous to the standard Dapagliflozin was calculated and reported to be acidic 3.64 $\%)$, alkaline (0.68\%), Oxidative (1.69 \%), Thermal (4.17\%),
Photolytic (2.99\%) and acidic (11.02\%), alkaline (6.80 \%), Oxidative (9.01\%), Thermal (11.66\%) and Photolytic (8.18\%) for acid hydrolysis, alkaline hydrolysis, oxidation, thermal and photolytic stability at $0.1 \mathrm{~N}$ and $01 \mathrm{~N}$ conditions respectively (table 8).

Table 8: Data of stress degradation studies dapagliflozin

\begin{tabular}{llll}
\hline Stress condition at 0.1 (N) & *mean peak area & *Drug recovered (\%) & *Drug decomposed (\%) \\
\hline Standard drug (untreated) & 551911 & 100 & - \\
Acidic degradation & 531807 & 96.36 & 3.64 \\
Alkaline degradation & 548162 & 99.32 & 0.68 \\
Oxidative degradation & 542556 & 98.31 & 1.69 \\
Thermal degradation & 528879 & 95.83 & 4.17 \\
Photolytic degradation & 535409 & 97.01 & 2.99 \\
Stress Condition at 01 (N) & $*$ mean peak area & $*$ Drug recovered (\%) & Drug decomposed (\%) \\
Standard drug (untreated) & 551911 & 100 & - \\
Acidic degradation & 491085 & 88.98 & 11.02 \\
Alkaline degradation & 514384 & 93.20 & 6.80 \\
Oxidative degradation & 502181 & 90.99 & 9.01 \\
Thermal degradation & 487571 & 88.34 & 11.66 \\
Photolytic degradation & 506762 & 91.82 & 8.18 \\
\hline
\end{tabular}

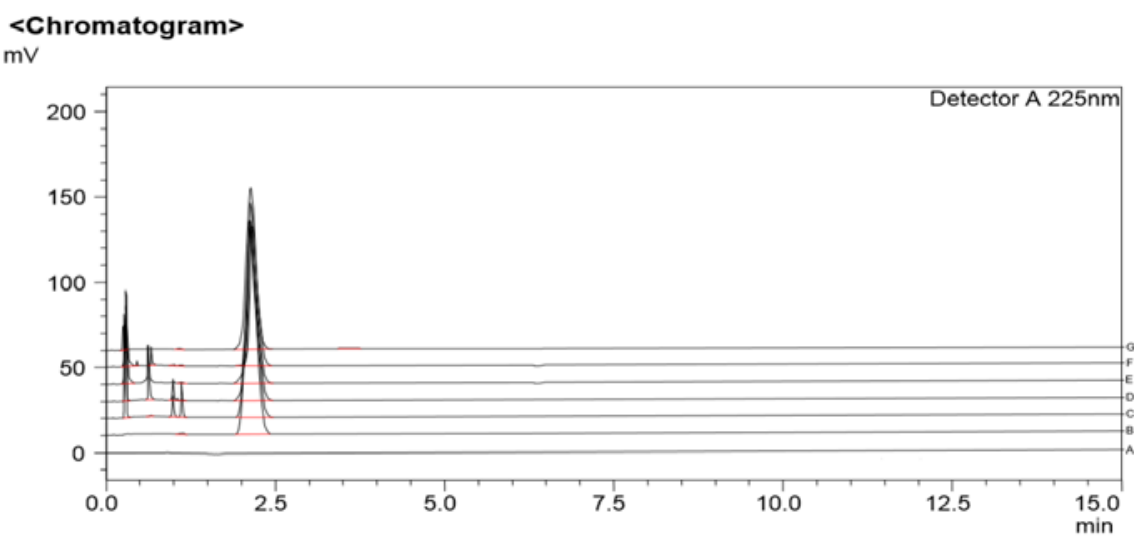

Fig. 4: Chromatogram of dapagliflozin in photolytic degradation A-Blank, B-Standard, C-Acidic, D-Alkaline, E-Oxidative, F-Thermal, GPhotolytic degradation

\section{DISCUSSION}

As of now, there is no RP-HPLC method reported on Dapagliflozin elution within specific chromatographic conditions, which is highly effective and more economical. Whatever was reported till date has its own drawbacks such as few experiments consumed more organic phases and at the same time, failed to integrate the degradants. Hence, there is a need of identifying the right analytical method which elutes the drug within a specific time limit when it is present alone in API or in the form of finished pharmaceutical formulation with other oral anti-hyperglycemic agents. Currently available analytical method mainly focuses on estimating the Dapagliflozin in combination with other oral antihyperglycemic agents [4-24].

To optimize the developed method various chromatographic conditions are implied such as different mobile phase, flow rate, different column, selected column with different temperature and different wavelengths during the chromatographic trail runs. Buffers with $\mathrm{pH} 4-6$, column temperature $28{ }^{\circ} \mathrm{C}$ and flow rate $1.0 \mathrm{ml} / \mathrm{min}$ provided promising results with minimal errors such as increased peak width, moderate retention time and different Tailing factors compared with previous reported studies $[3,8,9,10]$.

Ideal parameters were decided based on chromatographic results obtained for Dapagliflozin at $\mathrm{pH} 4$, column temperature $28{ }^{\circ} \mathrm{C}$ and Flow rate $1.0 \mathrm{ml} / \mathrm{min}$; the developed method improved the tailing factor and robustness of the study during its trial runs. Phosphate buffer $\mathrm{pH}$ 4: Acetonitrile: Methanol ratio of 55:40:05 $(\mathrm{v} / \mathrm{v} / \mathrm{v})$ was selected as mobile phase and diluents for this proposed method. Above mobile phase, composition eluted the analyte within 3 min with improved tailing factor compared to the previous reports [8-10].

Analysis of the marketed formulation was carried out on the basis of peak area obtained for Dapagliflozin in UV detector detection wavelength $225 \mathrm{~nm}$. The retention time obtained for Dapagliflozin was found at $2.12 \pm 0.5 \mathrm{~min}$. The calibration curve response was recorded linear with the concentration range of $10-120 \mu \mathrm{g} / \mathrm{ml}$. Good peak symmetry with exceptional separation observed for validation parameters such as Linearity, Accuracy, Precision and Robustness during evaluation.

The analytical method has been validated as per the guidelines provided by ICH $[25,26]$ and found more linear towards its range of concentration $10 \mu \mathrm{g} / \mathrm{ml}-120 \mu \mathrm{g} / \mathrm{ml}$. Simple mobile composition of phosphate buffer: acetonitrile and methanol used in this study with the final pH less than 3.4 eluted the analyte at RT $2.12 \pm 0.5 \mathrm{~min}$, Recovery percentage was found more accurate $(98.90,99.10,98.51)$, no significant changes in deliberate variation method $(1.63,1.79$, $1.26,1.65)$, precision values fell less than 2 during intra and interday analysis, an acceptable limit as per ICH criteria compared to the reported methods [17-20].

Mild to moderate degradation occurred for the samples exposure to Thermal and oxidative conditions in forced degradation studies (11.02, 6.80, 9.01, 11.66, 8.18\%), and its \% RSD and error fall less than $2 \%$ that indicates the proposed method has good stability and also the degraded products not altered the peak area RT at any of its conditions; therefore it will be utilized to study degradation products of Dapagliflozin API and Pharmaceutical formulation. 
Based on the Statistical data analysis report the developed method was found more reliable, cost-effective and highly reproducible.

\section{CONCLUSION}

The research work was promising, unique and less time-consuming, with a minimum amount of solvent utilization for estimating the Dapagliflozin. Hence, this method was found to be simple, rapid, economical, specific, accurate, precise and robust. Stress degradation studies revealed that Dapagliflozin can withstand the alkaline, oxidation conditions; meanwhile, in acidic, thermal and photolytic conditions mild degradation occurs over a period of time exposure. Based on the above experimentation results, our proposed method can be utilized as simple, rapid, economical and stabilityindicating RP HPLC method to estimate and quantify degradation products of Dapagliflozin in API and pharmaceutical formulation.

\section{ACKNOWLEDGMENT}

The authors felt grateful and happy the way we received support from Shree icon laboratories and Anjuman-i-islam School of Pharmacy for allowing us to conduct the research work in their Central Instrument Room (CIR) facility.

\section{FUNDING}

The authors declare that they have not received any funds to carry over this research work from any organizations/agencies.

\section{AUTHORS CONTRIBUTIONS}

All the authors contributed equally.

\section{CONFLICT OF INTERESTS}

The authors declared that there were no conflicts of interest for this study.

\section{REFERENCES}

1. Olokoba Abdulfatai B, Obateru Olusegun A, Olokoba Lateefat B. Type 2 diabetes mellitus: a review of current trends. Oman Med J. 2012;27(4):269-73. doi: 10.5001/omj.2012.68, PMID 23071876.

2. White John R. Sodium-glucose cotransporter 2 inhibitors. Med Clin North Am. 2015;99(1):131-43. doi: 10.1016/j.mcna.2014.08.020, PMID 25456647.

3. Verma MV, Patel CJ, Patel MM. Development and stability indicating HPLC method for Dapagliflozin in API and pharmaceutical dosage form. Int J App Pharm. 2017;9(5):3341. doi: 10.22159/ijap.2017v9i5.19185.

4. Mante Gajanan Vithoba, Gupta Krishna Radheshyam, Hemke Atul Tryambakrao. Estimation of dapagliflozin from its tablet formulation by UV-spectrophotometry. Pharm Methods. 2017;8(2):102-7. doi: 10.5530/phm.2017.8.16.

5. De Meira Rafaela Zielinski Cavalheiro, Maciel Aline Biggi, Murakami Fabio Seigi, de Oliveira Paulo Renato, Bernardi Larissa Sakis. In vitro dissolution profile of dapagliflozin: development, method validation, and analysis of commercial tablets. Int J Anal Chem. 2017. doi: 10.1155/2017/2951529, PMID 28831283.

6. Murugesan A, Mathrusri Annapurna M. Validated and quantified stability-indicating stress degradation study of oral anti-diabetic agent canagliflozin by RP-HPLC method. Int J App Pharm. 2021;13(5):358-63.

doi: 10.22159/ijap.2021v13i5.41005.

7. Gopal NM, Sridhar C. A validated stability indicating ultraperformance liquid chromatographic method for simultaneous determination of metformin hydrochloride and Empagliflozin in bulk drug and tablet dosage form. Int J App Pharm. 2017;9(3):45-50. doi: 10.22159/ijap.2017v9i3.17441.

8. Aneesh Patel, Dr. Lavakesh Omray, Pushpendra Soni. Method development for simultaneous estimation of Dapagliflozin and saxagliptin in fixed-dose combination and validation on UV spectroscopy. J Pharm. 2020;9(3);2536-43.

9. Jani BR, Shah KV, Kapupara PP. Development and validation of UV spectroscopic first derivative method for simultaneous estimation of dapagliflozin and metformin hydrochloride in synthetic mixture. J Bioequiv Stud. 2015;1(1):102.
10. Suthar Asim M, Prajapati Laxman M, Joshi Amit K, Patel Jimish R, Kharodiya Mohammadali L. Estimation of saxagliptin hydrochloride and dapagliflozin propendiol monohydrate in combined dosage form. J Innov Appl Pharm Sci. 2018;3(2):1-7.

11. Ameeduzzafor, El-Bagory Ibrahim, Alruwaili Nabil K, Syed Sarim Imam, Fadhel Ahmed Alomar, Mohammed H Elkomy, Naveed Ahmad, Mohammed Elmowafy. Quality by design (QbD) based development and validation of bioanalytical RPHPLC method for dapagliflozin: Forced degradation and preclinical pharmacokinetic study. J Liq Chromatogr R T 2019;1520-572X.

12. Aubry Anne Francoise, Gu Huidong, Magnier Reynald, Morgan Ling, Xu Xiaohui, Tirmenstein Mark, Wang Bonnie, Deng Yuzhong, Cai Jinnan, Couerbe Philippe, Arnold Mark. Validated LC-MS/MS methods for the determination of dapagliflozin, a sodium-glucose co-transporter 2 inhibitor in normal and ZDF rat plasma. Bioanalysis. 2010;2(12):2001-9. doi: 10.4155/bio.10.139, PMID 21110743.

13. Adluri P, Y SK. Development and validation of sensitive LC-ESIMS/MS method for the simultaneous estimation of dapagliflozin and saxagliptin in human plasma. Int J Pharm Pharm Sci. 2019;11(4):55-9. doi: 10.22159/ijpps.2019v11i4.31249.

14. Suma BV, RD, Shenoy Premnath. A new high performance thin layer chromatographic method development and validation of dapagliflozin in bulk and tablet dosage form. Int J Pharm Pharm Sci. 2019;11(8):58-63. doi: 10.22159/ijpps.2019v11i8.34339.

15. Omar Mahmoud A, Ahmed Hytham M, Batakoushy Hany A, Abdel Hamid Mohamed A. Fluorescence spectroscopy for determination of dapagliflozin in pure form and its tablets formulation; application to content uniformity testing. Spectrochim Acta A Mol Biomol Spectrosc. 2020;241:118642. doi: 10.1016/j.saa.2020.118642, PMID 32622048.

16. Maher HM, Abdelrahman AE, Alzoman NZ, Aljohar HI. Stabilityindicating capillary electrophoresis method for the simultaneous determination of metformin hydrochloride, saxagliptin hydrochloride, and dapagliflozin in pharmaceutical tablets. Journal of Liquid Chromatography and Related Technologies. 2019;42(5-6):161-71. doi: 10.1080/10826076.2019.1590208.

17. Navya Sree V, Bhavyasri K, Sumakanth M, Swethasri R. Estimation of dapagliflozin in pure and marketed formulation by validated reverse phase-high performance liquid chromatographic method. Int J Life Sci Pharm Res. 2020;10(4)70-84:70-84. doi: 10.22376/ijpbs/lpr.2020.10.4.

18. Debata Jitendra, Kumar Sundeep, Jha Sajal Kumar, Khan Amjad. A new RP-HPLC method development and validation of dapagliflozin in bulk and tablet dosage form. Int J Drug Dev Res. 2017;9:48-51.

19. Manoharan Gunasekar, Ismaiel Ahmed M, Ahmed Zeyad Mohammed. Stability-indicating RP-HPLC method development for simultaneous determination and estimation of dapagliflozin in raw and tablet formulation. J Chem Res. 2018;3(2):159-64.

20. Sura Sreenivasulu, Modalavalasa Rameswara Rao, Kothapalli Chandrasekhar B. Validation of a newly developed stabilityindicating RP-liquid chromatographic method for the quantitative determination of dapagliflozin. Pharm Chem. 2018;10(1):93-102.

21. Deepan Thiyagarajan, Dhanaraju Magharla Dasaratha. Stability indicating HPLC method for the simultaneous determination of dapagliflozin and saxagliptin in bulk and tablet dosage form. Curr Issues Pharm Med Sci. 2018;31(1):39-43. doi: 10.1515/cipms-2018-0009.

22. Suthar Nima, Marvaniya Vanita, Patni Pragnesh. Stability indicating method development and validation for the simultaneous estimation of dapagliflozin and saxagliptin in synthetic mixture by HPLC. Pharm Sci Monit. 2018;9(2):112-28.

23. Goday S, Shaik AR, Avula P. Development and validation of a LC-ESI-MS/MS based bioanalytical method for dapagliflozin and saxagliptin in human plasma. Ind J Pharm Educ Res. 2018;52(4s):S277-86. doi: 10.5530/ijper.52.4s.108.

24. Singh N, Bansal P, Maithani M, Chauhan Y. Development and validation of a stability-indicating RP-HPLC method for 
simultaneous determination of dapagliflozin and saxagliptin in fixed-dose combination. New J Chem. 2018;42(4):2459-66. doi: 10.1039/C7NJ04260D.

25. ICH guideline Q1A (R2). Stability testing of new drug substances and products. ICH; 2003. Available from: https://www.ich.org/fileadmin/Public_Web_Site/ICH.Products
/Guidelines/Quality/Q1A_R2/Step4/Q1A_R2_Guideline.pdf. [Last accessed on 15 Sep 2021]

26. ICH guideline Q2. Validation of analytical procedures: text and methodology. Vol. R1. ICH; 2005. Available from: http://www.ich.org/fileadmin/Public_Web_Site/ICH

Products/Guidelines/Quality/Q2_R1/Step4/Q2_R1_Guideline.pdf. [Last accessed on 15 Sep 2021] 